\title{
The Protection of the Patients' Privacy in Anesthesiology Clinic
}

\author{
$\mathrm{Na} \mathrm{WANG}^{1}$ and Jin-guo WANG ${ }^{2, *}$ \\ ${ }^{1}$ Department of Anesthesiology, The First Hospital of Jilin University, China \\ ${ }^{2}$ Department of Urology, The First Hospital of Jilin University, China \\ ${ }^{*}$ Corresponding author
}

Keywords: Medical examination, Privacy, Anesthesiology.

\begin{abstract}
Patients will fall asleep under anesthesiology in most cases, so they will lose their consciousness to protect themselves. Therefore, the anesthetists carry on more duties to protect the patients' privacy.
\end{abstract}

\section{Introduction}

Medical examination is an important part of modern medical service is indispensable. In this paper, the rationality of the medical examination and the related problems of research, can help people more in-depth and systematic understanding of the basic features of the medical check behavior and internal mechanism, benefit to guide and standardize the practice of medical examination, to improve medical service quality, reduce medical service cost and establish the harmonious doctor-patient relationship, can also be used for medical and health departments set up a scientific medical examination provides some references for the supervision and management of the specification.

\section{The Current Status of Anesthesiology Clinic}

\section{More Patients Require Anesthesia in Medical Examination}

Analysis from the perspective of a doctor to see, there are. Some clinical less experienced staff, as much as possible in order to be able to timely and accurately find the patient's health problems and achieve accurate disease diagnosis and treatment results, and broad use of technology to the medical examination.

Some doctors medical technology itself is no problem, but considering the reality of the doctor-patient relationship is not harmonious, as much as possible in order to avoid missed diagnosis or misdiagnosis phenomenon of trouble, allowing the patient to do some more checking to ensure that the medical risk minimization [1].

\section{Patients Lose Ability to Protect Themselves during Anesthesia}

Different behavior in the medical inspection link, in the form of rational forms are different: the implementation of the medical examination from the decision-making process, most health inspection of the implementation of the project is made up of choices and decisions on behalf of the staff, it is technical authority of the medical behavior, a small number of medical examination is applied by patients and medical staff agreed to after implementation, that is a reflection of patient autonomy in medical treatment. From the department of medical link, the implementation of the medical examination project technician according to the examination application, in accordance 
with the inspection procedure specification, and the inspection results to a predetermined program submitted to the patient or clinical medical personnel. Visible, the form of a medical examination rational medical staff is only required to implement the medical examination behavior conforms to the operation regulation of medical examination and operation process, without considering the real purpose of the medical examination and the final effects of ethical and economic issues. The medical check the substantial rationality mainly refers to the medical check program meets the medical ethics and operation specification, whether to respect the patient's personality and self-esteem, conformed to the value judgment of medical examination behavior and properties [2].

\section{Medical Examination Practice}

Medical examination practice, its essence rationality first performance, the necessity of the implementation of medical examination in clinical diagnosis and treatment to the medical personnel, can clear condition and confirmed by traditional diagnosis and treatment means, which don't have to use additional medical examination. Moreover is the medical check the effectiveness of the use and economy, and should be according to the illness and the patient's specific situation, combined with the characteristics of medical examination means, try to choose the most suitable and cost less to patients medical examination technology. In addition, in the medical examination behavior of concrete operation process, according to the special physical and disorders of patients, they intend to adjustment of medical examination technology parameters and operating procedures, technician humanized service is also an important medical check real rational performance [3].

\section{The Status of the Clinic}

The design and develop specific management practices, the medical examination to in-depth research and scientific reasoning, only fully embodies medical examination standards is the real essence of rational behavior guidance and effectiveness. And evaluation on the rationality of medical examination not only to a certain behavior standard is the only reference, at the same time also should pay attention to the essence of the particular scenario specific medical examination behavior is reasonable, should not only adhere to form rational assessment of standardization, also want to conform to the essence of rational human nature, should be in the medical check form an organic combination of rationality and substantive rationality, under the principle of centering on the patients health interests effectively maintain, as far as possible to reduce the economic burden of patients and to respect the principal rights of patients, earnestly implement comprehensive scientific evaluation on the rationality of the medical examination [4]. The perspective of "limited rationality" proposed "satisfied with the decision theory of management strategy, managers or decision makers think daily work to master the related information and the ability to process information is limited, the behavior of rational groove is only between unlimited rationality and irrationality of" bounded rationality ", was "given" environment limits the real reason, is not complete and determine to anticipate every possible solution of the implementation of the consequences, as a result, human can only "satisfactory" as the result of the act in the reasonable judgment criterion, so as to make the "satisfied with the decision theory" more accord with the actual situation in real life." Limited rationality" effectively makes up the defect of the infinite ration and reduces the decision-making costs, improves the efficiency of the decision-making, has more practical value. 


\section{The Methods of Protection}

\section{The Improvement of Medical Service}

To external medical examination service form, the hospital management of specific measures mainly include: government for admittance of medical examination technology and technology, to medical check pricing and price adjustment of the project, as well as the regulation of mutual recognition with the result of medical examination system and so on. Inside the hospital for medical examination of the specific management measures are: one is the management of the medical department internal measures, including the technician of performance appraisal, education, training and work schedules, and daily use of medical facilities, maintenance and management measures such as depreciation. Second, implement medical examination for clinical medical staff's performance appraisal method, clinical departments and medical department management systems for the work of cohesion [5]. Different hospital for medical examination management system and measures have very big difference, this may not only directly affect the department of medical staff's work enthusiasm, thus affect the supply of medical inspection work quality, at the same time, also affects the clinical medical staff on the using effect and efficiency of medical examination project, which will ultimately affect the rationality of the medical examination questions.

\section{The Involvement of the Government}

Although governments around the world for medical service degree of regulation and oversight of the methods, means, and the content difference is very big, but the main aim of the government regulation is in order to alleviate the medical service market failure [6]. At present, the nature of the medical and health undertakings of our country is government to impose a certain benefits of public welfare undertakings, combined with our country medical service supply of main body is public ownership of the medical service, the government can use double qualification of administrative management and the resource owner to control and regulate medical behavior of medical institutions.

The government regulation on medical examination service in the new period is the main means of administrative means, economic means, legal means and so on. Specifically, the government's regulation is an important part in medical examination service buyers and investors directly, is between medical institutions or medical institutions and other sectors of medical examination business coordinator, is the authority of the medical examination information disclosure [7].

\section{Summary}

Many medical tests require anesthesia nowadays. Besides the safety of the patients, there are still other matters to concern, for example patients' privacy which is their rights to preserve. For example, ministry of health to make a series of specific provisions on the implementation of clinical pathway has been clear about the many single diseases must implement medical examination project, the incoming of the tort liability law of the People's Republic of China set some provision for medical tort and liability of constitutive requirements. 


\section{References}

[1] Matsuda S. An AHP analysis of knowledge and skills necessary to become an occupational physician and required under- and post-graduate education and training system. Journal of UOEH. 1996

[2] Sudeh Cheraghi-Sohi, Peter Bower. Can the feedback of patient assessments, brief training, or their combination, improve the interpersonal skills of primary care physicians? A systematic review. BMC Health Services Research. 2008

[3] Williams K. Self-assessment of clinical competence by general practitioner trainees before and after a six-month psychiatric placement. The British journal of general practice: the journal of the Royal College of General Practitioners. 1998

[4] Jansen J J, Tan L H, van der Vleuten C P, van Luijk S J, Rethans J J, Grol R P. Assessment of competence in technical clinical skills of general practitioners. Medical Education. 1995

[5] TAYLOR R B. Family medicine:current issue and future practice. Family Medicine-Practice. 1998

[6] Frank Castro, Leonard P. Caccamo, Kimbroe J. Carter, Barbara A. Erickson, William Johnson, Edward Kessler, Nathan P. Ritchey, Claudio A. Ruiz. Sequential Test Selection in the Analysis of Abdominal Pain. Medical Decision Making. 1996

[7] Taylor RB. Family medicine: current issues and future practice. Family Medicine-Principles and Practice. 1998 